\title{
Differences in the Involvement of Prostanoids from Kupffer Cells in the Mediation of Anaphylatoxin C5a-, Zymosan-, and Lipopolysaccharide-Dependent Hepatic Glucose Output and Flow Reduction
}

\author{
Sabine Pestel, Gerald Schlaf, Otto Götze, Kurt Jungermann*, and \\ Henrike L. Schieferdecker \\ Institute of Biochemistry and Molecular Cell Biology (SP, KJ, HLS) and Department of Immunology (GS, OG), \\ Georg-August-University Goettingen, Goettingen, Germany
}

\begin{abstract}
SUMMARY: Various inflammatory stimuli such as anaphylatoxin C5a, zymosan, and lipopolysaccharides (LPSs) have been reported both to enhance glucose output in the perfused rat liver and to induce prostanoid (ie, prostaglandin and thromboxane) release from Kupffer cells, the resident liver macrophages. Because prostanoids can enhance glucose output from hepatocytes, it was the aim of this study to compare the possible roles of prostanoids released after C5a, zymosan, and LPS in the mediation of hepatic glucose output. In perfused livers both C5a and zymosan immediately enhanced glucose output, reduced flow, and induced prostanoid overflow into the hepatic vein, but with different quantities and kinetics. Only the C5a-induced but not the zymosan-induced effects were abrogated by inhibitors of prostanoid signaling as the prostanoid synthesis inhibitor indomethacin and the thromboxane receptor antagonist daltroban. In contrast to C5a and zymosan, LPS had no effect on glucose output, flow rate, or prostanoid overflow. In isolated Kupffer cells, C5a and zymosan induced maximal release of prostaglandins $D_{2}$ and $E_{2}$ and of thromboxane $\mathrm{A}_{2}$ within a period of 0 to 2 minutes and 5 to 15 minutes, respectively. In pulse-chase experiments, maximal prostanoid release was already observed after 2 minutes of continuous stimulation with C5a, but only after 10 to 15 minutes of continuous stimulation with zymosan. LPS-dependent prostanoid release was not seen before 1 hour. Thus, even though C5a, zymosan, and LPS induced prostanoid release from Kupffer cells, only C5a quickly regulated hepatic glucose metabolism in a prostanoid-dependent manner (due to the kinetics and quantities of prostanoids released). (Lab Invest 2003, 83:1733-1741).
\end{abstract}

\begin{abstract}
$T$ he liver functions as an important defense organ by detoxifying drugs and micro- and macropathogens, by synthesizing and releasing pro- and anti-inflammatory mediators, and by initiating the acute-phase response. Other defense reactions are (a) an increased output of glucose, which serves as an electron donor for radical formation and as an energy substrate for enhanced metabolism during inflammation; and (b) a reduced flow rate for the easier adhesion and transmigration of leukocytes (Püschel and Jungermann, 1994). Short-term metabolic and hemodynamic changes were observed after infusion of complement activated serum (Muschol et al, 1991) or anaphylatoxins C3a (Püschel et al, 1993, 1996) or C5a (Püschel et al, 1996; Schieferdecker et al, 1999), which are generated during complement activation. It was shown that C5a did not act directly on hepatocytes
\end{abstract}

DOI: 10.1097/01.LAB.0000101727.89483.37

${ }^{*}$ Deceased.

Received February 12, 2003.

Address reprint requests to: Dr. Henrike L. Schieferdecker, Institut für Biochemie und Molekulare Zellbiologie, Georg-August-Universität Göttingen, Humboldtallee 23, D-37073 Göttingen, Germany. E-mail: hschief@gwdg.de
(Hespeling et al, 1995; Schieferdecker et al, 1998). This was supported by the finding that $\mathrm{C} 5$ a receptors (CD88) were not expressed by hepatocytes but only by nonparenchymal cells, ie, by Kupffer cells (KCs), hepatic stellate cells, and sinusoidal endothelial cells in decreasing amounts (Schieferdecker et al, 1997; Schlaf et al, 1999). The C5a-dependent glucose output and flow reduction were shown to be solely mediated by prostanoids, ie, prostaglandins and thromboxane (Schieferdecker et al, 1999), released from KCs (Hespeling et al, 1995) and hepatic stellate cells (Schieferdecker et al, 1998). Whereas prostaglandins directly enhanced glucose output from hepatocytes, thromboxane $A_{2}$ indirectly induced metabolic effects via flow reduction (Schieferdecker et al, 1999).

Zymosan, an extract of yeast membranes, and lipopolysaccharides (LPSs), components of the outer cellular membrane of Gram-negative bacteria, have been reported to (a) mediate glucose output either from hepatocytes or from the liver (Casteleijn et al, 1987; Dieter et al, 1987b) and (b) induce prostanoid output from KCs (Birmelin and Decker, 1984; Dieter et al, 1989; Grewe et al, 1992; Püschel et al, 1993). Nevertheless, it was not yet shown whether zymosan or LPS, like C5a, prostanoid-dependently increased glucose output or reduced flow in the liver. 
It was the aim of this study to investigate the possible roles of prostanoids released from KCs after stimulation with zymosan and LPS in comparison with $\mathrm{C5a}$ in the regulation of short-term glucose output and flow reduction in the perfused rat liver.

\section{Results}

\section{Enhanced Glucose Output and Reduced Flow Rate in the Isolated Perfused Rat Liver after Stimulation with rrC5a or Zymosan but not LPS}

Infusion of 100 nм rrC5a for 30 seconds in the in situ perfused liver immediately enhanced glucose output with a maximum after 3 minutes and reduced flow with a maximum after 2 minutes. Both effects regained baseline levels within 6 minutes (Fig. 1), as shown previously (Püschel et al, 1996; Schieferdecker et al, 1999). These effects were paralleled by an overflow of prostaglandin $\mathrm{D}_{2}\left(\mathrm{PGD}_{2}\right)$ (Fig. 1), as well as prostaglandin $E_{2}\left(P E_{2}\right)$ and thromboxane $A_{2}\left(T_{X} A_{2}\right)$ (not shown) into the hepatic vein. This overflow represents the difference between prostanoid release from nonparenchymal cells and prostanoid binding or degradation by hepatocytes.

Infusion of $0.5 \mathrm{mg} / \mathrm{ml}$ zymosan for 30 seconds enhanced glucose output and reduced flow as did rC5a, but with maxima at 2 minutes and 3 minutes, respectively. Thus, in contrast to $\mathrm{rrC5a}$, the metabolic effect preceded the hemodynamic effect (Fig. 1). Also in contrast to rrC5a, glucose levels did not regain baseline levels, and the strongly reduced flow rate levels persisted over a period of more than 15 minutes (not shown). Like the effects of $\mathrm{rrC5a}$, the metabolic and hemodynamic actions of zymosan were also accompanied by an enhanced $\mathrm{PGD}_{2}$ overflow. However, peak levels of $\mathrm{PGD}_{2}$ overflow after zymosan were more than 10-fold lower than after rrC5a (Fig. 1; note the different scalations). Also the total $P G D_{2}$ overflow within 10 minutes was almost 10-fold lower after zymosan than after rrC5a (Fig. 2).

In contrast to $\mathrm{rrC5a}$ or zymosan, $100 \mathrm{ng} / \mathrm{ml}$ LPS infused for 30 seconds failed to influence glucose output and flow rate (Fig. 1). Neither stimulation with higher LPS concentrations (up to $10 \mu \mathrm{g} / \mathrm{ml}$ ), nor longer infusion periods (up to 5 minutes) had any metabolic or hemodynamic effects (not shown). Also, no enhancement in $\mathrm{PGD}_{2}$ overflow was observed after LPS stimulation (Fig. 1).

\section{Inhibition of rrC5a- but not Zymosan-Induced Glucose Output and Flow Reduction by the Prostanoid Synthesis Inhibitor Indomethacin and the $\mathrm{TXA}_{2}$-Receptor Antagonist Daltroban}

The prostanoid synthesis inhibitor indomethacin completely blocked rrC5a-induced $\mathrm{PGD}_{2}$ overflow, while glucose output and flow reduction were reduced to about 40\% (Fig. 2) as described previously (Schieferdecker et al, 1999). In the additional presence of the $\mathrm{TXA}_{2}$-receptor antagonist daltroban, both the metabolic and the hemodynamic effects were blocked totally (Fig. 2) (Schieferdecker et al, 1999). Also zymosan-induced $\mathrm{PGD}_{2}$ overflow was almost completely inhibited in the presence of indomethacin (Fig. 2). However, in contrast to the rrC5a-induced effects, zymosan-induced glucose output and flow reduction were neither influenced by indomethacin alone nor by the combination of indomethacin and daltroban. This clearly shows that prostanoids were not involved in the mediation of the zymosan-induced metabolic and hemodynamic effects.

\section{Different Kinetics of Prostanoid Release from Cultured KCs after Stimulation with rrC5a, Zymosan, and LPS}

$\mathrm{PGD}_{2}, \mathrm{PGE}_{2}$, and $\mathrm{TXA}_{2}$ release from KCs strongly differed after stimulation with $\mathrm{rC} 5 \mathrm{a}$, zymosan, and
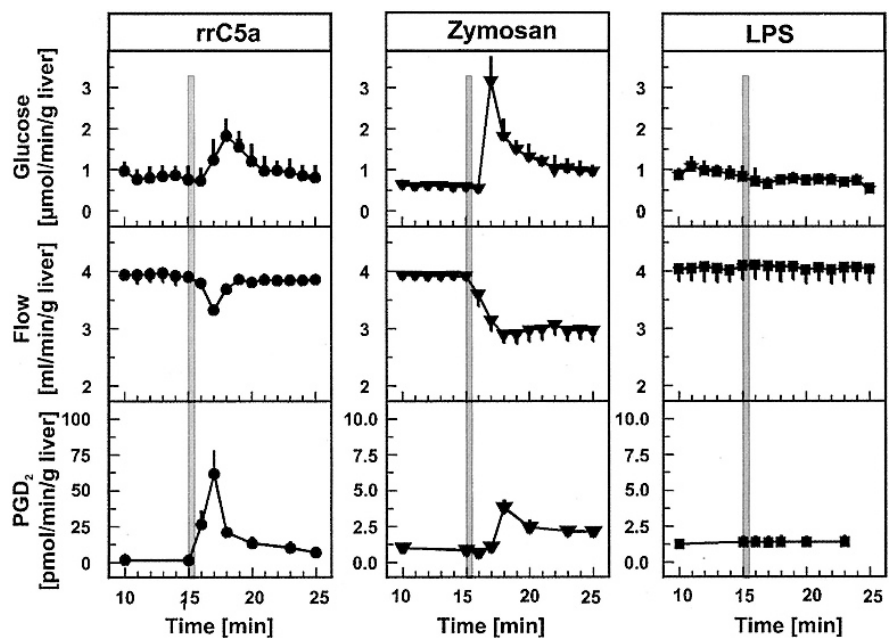

Figure 1.

Glucose output, flow rate, and prostaglandin $\mathrm{D}_{2}\left(P G D_{2}\right)$ overflow in the perfused rat liver after stimulation with rrC5a, zymosan, or lipopolysaccharide (LPS). Isolated rat livers were perfused in a nonrecirculating manner. After 30 minutes preperfusion, rrC5a, zymosan, or LPS were infused for 30 seconds (gray bars) to final concentrations of $100 \mathrm{~nm}(1 \mu \mathrm{g} / \mathrm{ml}), 0.5 \mathrm{mg} / \mathrm{ml}$, or $100 \mathrm{ng} / \mathrm{ml}$, respectively. Glucose concentrations in the fractionated effluate were determined in a standard assay with glucose dehydrogenase and $\mathrm{PGD}_{2}$ by radioimmunoassay. Note the different scalations of the $y$ axes used for the demonstration of $\mathrm{PGD}_{2}$ overflow after zymosan and LPS compared with rrC5a. Values are means \pm SEM of three to five independent experiments. 


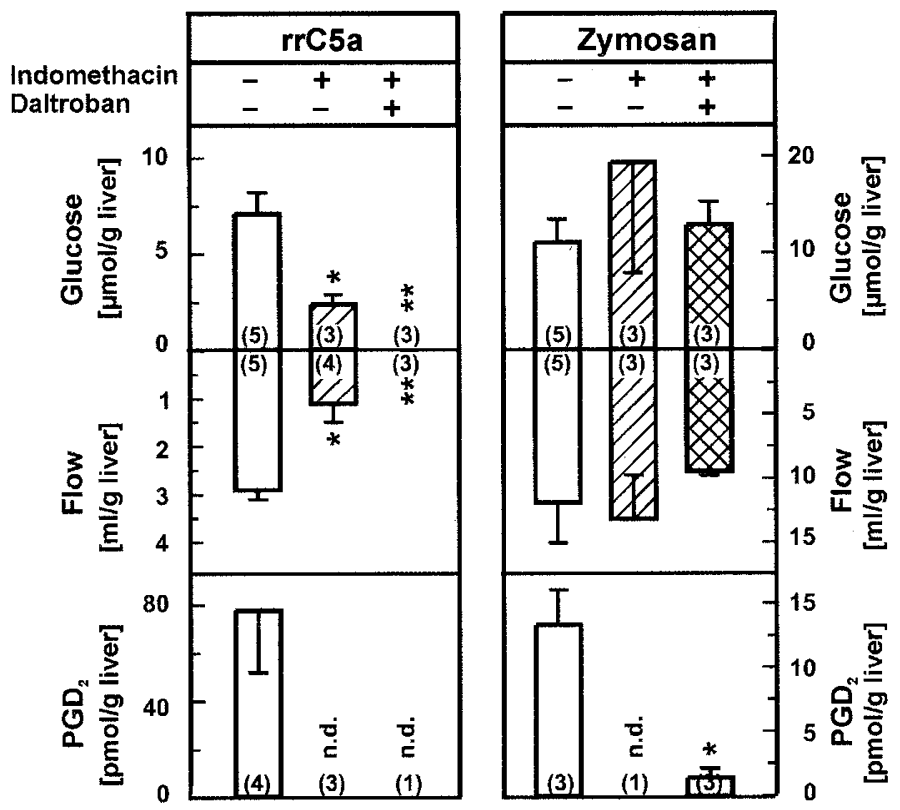

Figure 2.

Glucose output, flow rate, and prostaglandin $\mathrm{D}_{2}\left(P G D_{2}\right)$ overflow in the perfused rat liver after stimulation with rrC5a and zymosan in the absence or presence of the prostanoid synthesis inhibitor indomethacin and the thromboxane receptor antagonist daltroban. Rat livers were perfused and stimulated with $100 \mathrm{~nm}(1 \mu \mathrm{g} / \mathrm{ml}) \mathrm{rrC5a}$ or $0.5 \mathrm{mg} / \mathrm{ml}$ zymosan as described in Figure 1. Where indicated, indomethacin and/or daltroban (final concentration $20 \mu \mathrm{m}$ in $0.1 \%$ dimethyl sulfoxide each) were added to the perfusion medium at 10 minutes prior to stimulation. Note the different scalations on the $y$ axes. Values were calculated as areas under the curves and are means \pm SEM of one to five independent experiments (numbers in parentheses). ${ }^{*} p<0.05,{ }^{* *} p<0.01=$ significant differences compared with rrC5a- or zymosan-stimulated controls (Student's $t$ test for unpaired samples). n.d. $=$ not detectable.

LPS, respectively (Fig. 3). RrC5a as well as zymosan enhanced the release of $P G D_{2}, P G E_{2}$, and $T X A_{2}$ within the first 10 minutes. At this time point, the maximum of
rrC5a-dependent prostanoid release was already reached, whereas zymosan further enhanced prostanoid output within 1 hour to about 10-fold higher levels
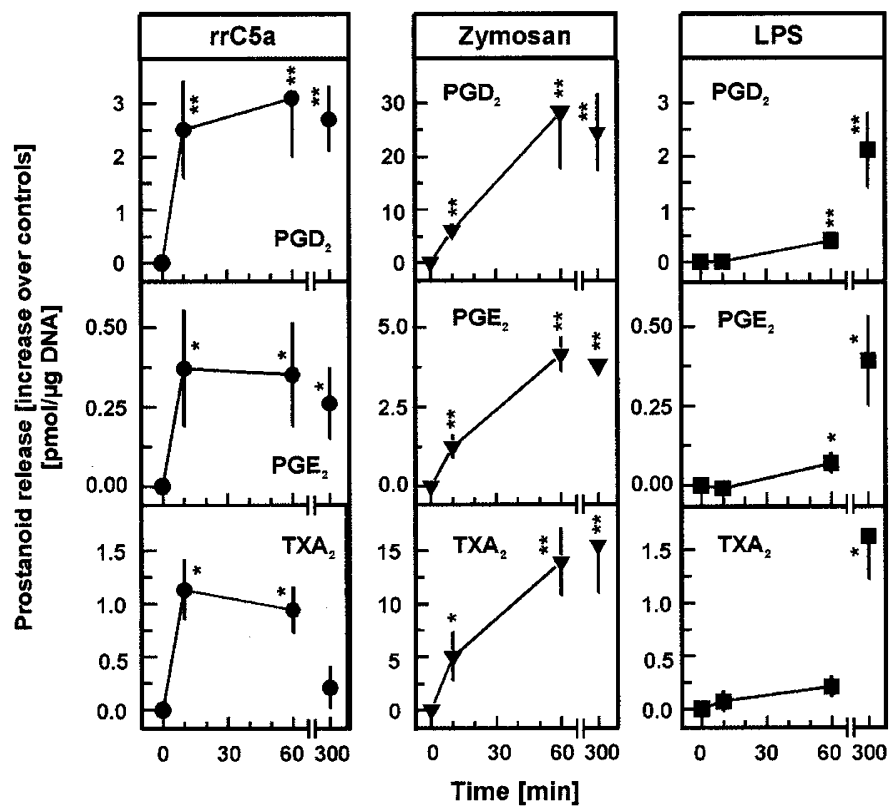

Figure 3.

Release of prostaglandin $(P G) \mathrm{D}_{2}, \mathrm{PGE}_{2}$, and thromboxane $(T X) \mathrm{A}_{2}$ from cultured Kupffer cells after stimulation with rrC5a, zymosan, or lipopolysaccharide (LPS). Kupffer cells, cultured for 3 days, were transferred to HBSS and after 10 minutes preincubation were stimulated with $100 \mathrm{~nm}(1 \mu \mathrm{g} / \mathrm{ml}) \mathrm{rrC5a}, 0.5 \mathrm{mg} / \mathrm{ml}$ zymosan, or $100 \mathrm{ng} / \mathrm{ml}$ LPS. At the indicated time points, aliquots of the supernatants were shock-frozen and prostanoid release was determined later either by radioimmunoassay $\left(\mathrm{PGD}_{2}\right)$ or by ELISA ( $\mathrm{PGE}_{2}$ and TXB ${ }_{2}$, the stable decomposition product of $\mathrm{TXA}_{2}$ [See "Materials and Methods"]). Note the different scalations on the $y$ axes. Values are shown as increases compared with unstimulated controls and are means \pm SEM of three to five independent experiments. ${ }^{*} p<0.05,{ }^{\star \star} p<$ $0.01=$ significant differences compared with unstimulated controls (Student's $t$ test for unpaired samples). 
than those induced by rrC5a. The used rrC5a concentration of $100 \mathrm{~nm}$, a concentration that was reached in in vitro experiments in human peripheral blood after complete activation of the complement system (Schulze and Götze, 1986), had previously been shown to increase prostanoid output from KCs maximally (Hespeling et al, 1995). Thus, the higher prostanoid output after zymosan was not due to the use of a submaximal rrC5a concentration.

In contrast to rrC5a and zymosan, LPS at a concentration of $100 \mathrm{ng} / \mathrm{ml}$, ie, a concentration that is at the upper limit of LPS levels reached under severe pathophysiologic conditions (Brandtzaeg et al, 1989), failed to increase the release of $P \mathrm{PD}_{2}, \mathrm{PGE}_{2}$, and $\mathrm{TXA}_{2}$ after 10 minutes. LPS slightly enhanced $\mathrm{PGD}_{2}$ and $P \mathrm{PE}_{2}$ output after only 1 hour and strongly increased $\mathrm{PGD}_{2}$, $\mathrm{PGE}_{2}$, and $\mathrm{TXA}_{2}$ output to levels similar to those induced by rrC5a at 5 hours after treatment.

\section{Dependence of Zymosan- but not rrC5a-Induced Prostanoid Release from Cultured KCs on the Duration of Stimulation}

The experiments with perfused livers and isolated KCs brought up an obvious discrepancy: in perfused livers lower prostanoid release was observed after zymosan compared with rC5a, whereas in isolated $\mathrm{KCs}$ much higher prostanoid levels were reached after zymosan compared with rrC5a. It was thus investigated whether this was due to the different stimulation periods (30 seconds in the perfusion experiments and continuous stimulation in the cell culture experiments). Therefore, cultured KCs were stimulated with rC5a or zymosan for different time periods. After continuous stimulation with rC5a and zymosan, maximal prostanoid release was observed within a period of 0 to 2 minutes and 5 to 15 minutes, respectively (Fig. 4A). In experiments with discontinuous stimulation, incubation of $\mathrm{KCs}$ with rrC5a for only 2 minutes was sufficient to enhance $\mathrm{PGD}_{2}$ and $\mathrm{PGE}_{2}$ release maximally: Within the first 2 minutes, prostanoid release nearly reached maximal levels, and $P G D_{2}$ and $P G E_{2}$ concentrations increased only slightly within the following period of up to 30 minutes (Fig. 4B, left panel). Stimulation with rrC5a for 10 minutes did not lead to higher prostanoid levels within 30 minutes compared with stimulation for only 2 minutes. In strong contrast to rrC5a, stimulation of KCs with zymosan for 2 minutes resulted in only low prostanoid release after these 2 minutes, which only slightly increased within the following 30 minutes (Fig. $4 \mathrm{~B}$, right panel). Increasing the stimulation periods to 5, 10, and 15 minutes, respectively, further increased prostanoid output observed directly after the stimulation periods $(5,10$, or 15 minutes), as well as after the entire period of 30 minutes. Only after a stimulation period of 15 minutes did zymosan induce maximal prostaglandin levels as shown by the finding that stimulation for 30 minutes did not further increase prostaglandin output.
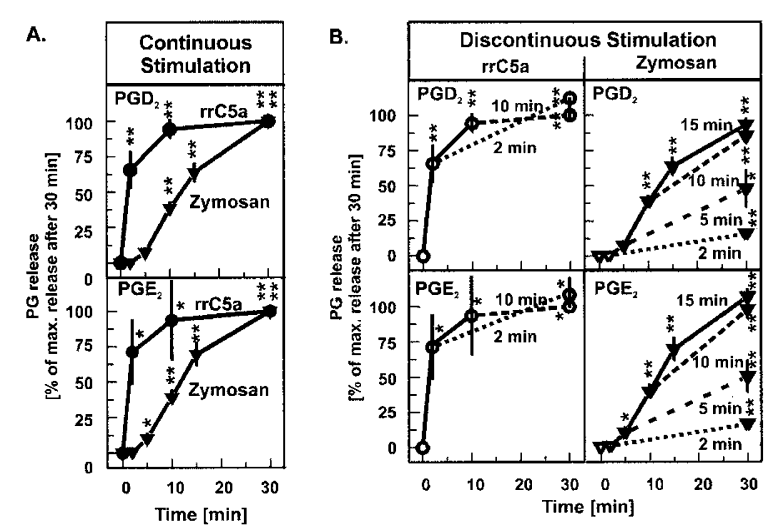

\section{Figure 4.}

Release of prostaglandin $(P G) D_{2}$ and $P G E_{2}$ from cultured Kupffer cells $(K C S)$ after stimulation with rrC5a or zymosan for different periods of time. KCs were cultured for 3 days with $0.5 \mu \mathrm{Ci}\left[1-{ }^{-14} \mathrm{C}\right]$ arachidonic acid added during the last 20 hours before the start of the experiments for labeling of phospholipids. KCs were then stimulated with $100 \mathrm{~nm}(1 \mu \mathrm{g} / \mathrm{ml})$ rrC5a or $0.5 \mathrm{mg} / \mathrm{ml}$ zymosan. (A) Continuous stimulation. KCs were stimulated for 30 minutes with rrC5a or zymosan. At the indicated time points, supernatants were shock-frozen, and $\mathrm{PGD}_{2}$ and $\mathrm{PGE}_{2}$ release was determined by thin layer chromatography. For calculation, PG concentrations after 30 minutes stimulation with rrC5a or zymosan were set equal to $100 \%$. (B) Discontinuous stimulation. The medium was changed from stimulus-containing medium for the pulse period to stimulus-free medium for the chase period 2, 5, 10, and 15 minutes after the start of stimulation. PG concentrations were determined once after the pulse and in addition 30 minutes after the initial stimulation (chase). For calculation, $P G$ concentrations at 30 minutes were set equal to $100 \%$; they represent the sum of pulse and chase. Values are means \pm SEM of three independent experiments. ${ }^{*} p<0.05,{ }^{* *} p<0.01=$ significant differences compared with $\mathrm{PG}$ concentrations at 0 minutes (Student's $t$ test for unpaired samples).

\section{Expression of Putative Receptors for C5a and Zymosan on KCs but not on Hepatocytes of Rat Liver}

Our data suggest that neither C5a nor zymosan directly induced glucose output from hepatocytes. This might be due to a lack of expression of the respective receptors on these cells. Indeed, C5a receptors (CD88) had been shown not to be expressed by hepatocytes, whereas they were strongly expressed by KCs (Schieferdecker et al, 1997; Schlaf et al, 1999). It was now shown additionally that the mRNA for the $\mathrm{C} 5 \mathrm{a} / \mathrm{C5}$ adesarg receptor C5L2 was only very weakly expressed by hepatocytes but was strongly expressed by KCs (Fig. 5). The receptors recently discussed to be mainly involved in zymosan signaling are dectin-1 alone or in association with toll-like receptor (TLR)2 and/or TLR4 (See "Discussion" section). Using mouse dectin-1 primers, no signals were obtained for rat KCs and hepatocytes (data not shown). However, in cells from mouse liver, dectin- 1 mRNA again was found to be only very weakly expressed by hepatocytes but was strongly expressed by KCs (Fig. 5). This suggests that the failing detection of dectin-1-specific mRNA in rat KCs might be due to a failing crossreactivity of the mouse primers with the so far unpublished rat sequence. An expression pattern similar to dectin-1 was also observed for the TLR molecules in that TLR4 mRNA and TLR2 mRNA were expressed only by KCs but not by hepatocytes (Fig. 5). 

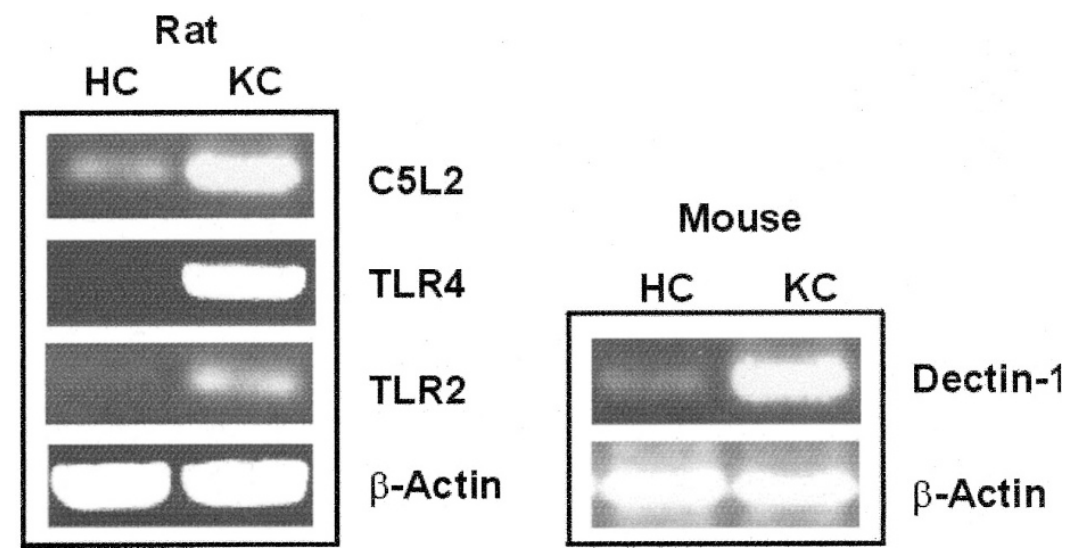

Figure 5 .

Detection of mRNA for the putative C5a and zymosan receptors C5L2, dectin-1, toll-like receptor (TLR)4 and TLR2 in Kupffer cells (KCS) but not hepatocytes by reverse transcription PCR. To isolate RNA, 48-hour-cultured KCs and hepatocytes (HCS) were scraped off the tissue culture dishes. After reverse transcription with oligo(dT) as primers, cytokine CDNA was detected by PCR with specific primers as indicated in Table 1. PCR products were visualized after electrophoresis in agarose gels by ethidium bromide staining.

\section{Discussion}

\section{Independence of Zymosan-Induced Short-Term Glucose Output and Flow Reduction from Prostanoids in the Perfused Liver}

In perfused rat livers, short-term stimulation with zymosan for 30 seconds strongly enhanced glucose output and reduced flow as did C5a (Fig. 1). In contrast to $\mathrm{C5a}$, the effects of zymosan were neither influenced by the prostanoid synthesis inhibitor indomethacin alone nor by the combination of indomethacin with the $\mathrm{TXA}_{2}$-receptor antagonist daltroban (Fig. 2). These results indicate that prostanoids were not involved in the mediation of the immediate metabolic and hemodynamic effects observed after short-term stimulation with zymosan. Because zymosan had previously been reported to strongly enhance prostanoid release from KCs (Birmelin and Decker, 1984; Püschel et al, 1993), the low levels of prostanoid overflow in perfused livers after zymosan as compared with C5a (Fig. 3), as well as the independence of zymosaninduced glucose output of prostanoids, might be due to differences in the kinetics of prostanoid release after zymosan and C5a, respectively. Indeed, zymosan increased prostanoid output from KCs as did C5a, but zymosan-induced in contrast to C5a-induced prostanoid release was strongly dependent on the duration of stimulation. Whereas 2-minute stimulation of KCs with $\mathrm{C} 5 \mathrm{a}$ was sufficient to induce maximal prostanoid release, 2-minute stimulation of $\mathrm{KCs}$ with zymosan resulted in only slightly enhanced prostanoid levels after 2 minutes, as well as after 30 minutes (Fig. 4). Under these conditions prostanoid levels induced by zymosan were $2 \%$ to $3 \%$ of those observed after C5a. Maximal prostanoid output was induced only after a 15-minute stimulation period (Fig. 4).

At first sight in contrast to the present study, it had previously been reported that zymosan-induced glucose output in the perfused rat liver might be in part prostanoid dependent (Dieter et al, 1987a). In that study glucose output after infusion of zymosan for 5 minutes was strongly inhibited by the leukotriene synthesis inhibitor nordihydroguaiaretic acid and was further reduced in the additional presence of indo-

Table 1. Oligonucleotide Primers

\begin{tabular}{llcc}
\hline Name & \multicolumn{1}{c}{ Sequence $\left(5^{\prime} \rightarrow 3^{\prime}\right)$} & GenBank accession no. & Position \\
\hline$\beta$-actin- $f$ & GAT ATC GCT GCG CTC GTC GTC & V01217 & $1253-1273$ \\
$\beta$-actin-r & CCT CGG GGC ATC GGA ACC & NM019178 & $480-495$ \\
TLR4-f & GCT GGA TTT ATC CAG GTG TG & $1462-1444$ \\
TLR4-r & CAC CAT TGA AGC TGA GGT C & XM_227315 \\
TLR2-f & GGC CAG ACA GCT ACC TGT GT & $2009-2028$ \\
TLR2-r & TTC TCC ACC CAA TAG GAA TC & $2306-2287$ \\
C5L2-f ${ }^{a}$ & GGA AAG AGT CCC GCC ACA GGC TTG G & XM_145404 & $200-224$ \\
C5L2-r ${ }^{a}$ & GAA GCC AAA GAG GAA TCG AAC AG & & $645-623$ \\
Dectin-1-f & AGG CCC TAT GAA GAA CTA CAG ACA & AF262985 & $1384-1407$ \\
Dectin-1- ${ }^{a}$ & TGG CCA GAC AGC ATA AGG AA & & $1830-1811$
\end{tabular}

f, forward; r, reverse; TLR, toll-like receptor.

${ }^{a}$ Because rat sequences for C5L2 and dectin-1 are not yet known, the mouse sequences were used for primer selection. In both cases, primer pairs were selected from a part of the sequence, which shows high homology with the human sequence. In addition, primers for C5L2 were chosen from a part of the sequence, which shows virtually no homology to the C5a receptor (CD88) sequence. 
methacin. However, together with the results presented here, these data most probably indicate that leukotrienes are responsible for glucose output induced within the first 30 seconds after zymosan stimulation, while prostanoids might further enhance zymosan-induced glucose output at later time points. This prostanoid-dependent part of zymosan-induced glucose output was not seen in our studies and was most likely due to the shorter stimulation periods used (30 seconds versus 5 minutes). This hypothesis is supported by another study demonstrating different mechanisms of zymosan-induced glucose output by (a) the soluble fraction of zymosan, which quickly stimulates glucose output with a nordihydroguaiaretic acid-inhibitable and thus leukotriene-dependent mechanism; and (b) the pellet fraction of zymosan, which enhances glucose release more slowly in an indomethacin-inhibitable and thus prostanoiddependent manner (Kimura et al, 1992). The observed differences in kinetics and maxima of glucose output and flow reduction after $\mathrm{C5a}$ and zymosan (Fig. 1) further emphasize the mediation of short-term metabolic and hemodynamic effects of C5a and zymosan via prostanoids and leukotrienes, respectively.

\section{Failure of LPS to Induce Short-Term Glucose Output and Flow Reduction in the Perfused Liver}

Infusion of LPS (100 ng/ml) for 30 seconds did not influence glucose output nor flow rates in perfused rat livers (Fig. 1). In agreement with these observations, LPS failed to induce prostanoid release from $\mathrm{KCs}$ within minutes but did so only after hours (Fig. 3) as described previously (Peters et al, 1990). In contrast to the present study, an earlier investigation had demonstrated immediately enhanced, prostanoid-dependent glucose output from rat liver after infusion of 100 $\mu \mathrm{g} / \mathrm{ml}$ LPS for 5 minutes (Casteleijn et al, 1987). The observed discrepancy could not be due to the different stimulation periods used (30 seconds versus 5 minutes), because in our study the infusion of 100 $\mathrm{ng} / \mathrm{ml}$ LPS for 5 minutes also failed to enhance glucose output and to reduce flow rates (not shown). Therefore, these differences may be ascribed more likely to the different concentrations used $(100 \mathrm{ng} / \mathrm{ml}$ and $100 \mu \mathrm{g} / \mathrm{ml}$, respectively). The LPS concentration of 100 $\mathrm{ng} / \mathrm{ml}$ used in our study is at the upper limit of LPS levels reached under severe pathophysiologic conditions such as meningococcal sepsis (Brandtzaeg et al, 1989). At higher concentrations LPS has been reported to exert effector functions on target cells independent of the "normal" CD14/TLR4-dependent mechanism (Alexander and Rietschel, 2001), eg, by intercalation into cellular membranes (Schromm et al, 1996). However, at the very high LPS levels of $100 \mu \mathrm{g} / \mathrm{ml}$, unspecific mechanisms (eg, the activation of residual complement factors) might also be effective. Thus, in contrast to the conclusions drawn from the previous study (Casteleijn et al, 1987), our data clearly demonstrate that LPSs at (patho)physiologically relevant concentrations do not play a role in the short-term enhancement of glucose output during inflammation.

\section{Involvement of Putative C5a and Zymosan Receptors in the Intercellular Signaling from KCs to Hepatocytes}

Previous investigations (Dieter et al, 1987b; Kimura et al, 1992; Püschel et al, 1996; Schieferdecker et al, 1999) and the present study have shown that neither C5a nor zymosan directly induced glucose output from hepatocytes. These substances elicited effector functions of hepatocytes only indirectly by means of intercellular communication (Hespeling et al, 1995; Mäck et al, 2001; Püschel et al, 1996; Schieferdecker et al, 1999). In agreement with these observations, putative receptors for $\mathrm{C5a}$ and zymosan were predominantly or even exclusively expressed by KCs but not or only scarcely by hepatocytes (Fig. 5).

It had been shown previously that the C5a receptor CD88 was expressed by KCs but not by hepatocytes (Schieferdecker et al, 1997; Schlaf et al, 1999). Also the mRNA for the C5a/C5adesarg receptor C5L2 (Cain and Monk, 2002; Ohno et al, 2000) was predominantly expressed by KCs (Fig. 5), whereas hepatocytes expressed C5L2 mRNA only very weakly (Fig. 5). However, this faint mRNA expression in hepatocytes obviously did not lead to the expression of functional C5L2 protein, because under normal conditions hepatocytes did not respond to C5a (Hespeling et al, 1995; Mäck et al, 2001; Schlaf et al, 1999) nor to C5adesarg (unpublished observations).

In isolated KCs C5adesarg, like C5a (Fig. 3), induced a strong prostanoid release (own unpublished observations). This effect of C5adesarg presumably was mediated by C5L2, which at least on the mRNA level was strongly expressed in KCs and had a 10-fold higher affinity for C5adesarg than CD88 (Cain and Monk, 2002). Whether the effect of C5a on prostanoid release from KCs (Fig. 3) and thus on prostanoidmediated glucose output from hepatocytes (Fig. 1) was mediated via the C5a receptor CD88 or via C5L2 cannot be decided from the present results. In transfected rat basophilic leukemia cells, C5L2 coupled to a pertussis-toxin-sensitive pathway (Cain and Monk, 2002), whereas CD88 was shown to couple to both pertussis-toxin-insensitive Galpha16- (Amatruda et al, 1993; Buhl et al, 1993) and pertussis-toxin-sensitive Gi proteins (Siciliano et al, 1990). Because the G protein coupling of the $\mathrm{C5a}$ receptor $\mathrm{CD} 88$ in rat KCs has not been elucidated so far, the inhibition of C5ainduced prostanoid release from KCs by pertussis toxin (own unpublished observations) could be interpreted as C5a signaling via C5L2 and coupling of CD88 in KCs to a pertussis-toxin-sensitive Gi protein. Data that support the involvement of CD88 rather than C5L2 in the mediation of $\mathrm{C} 5 \mathrm{a}$ effects in rat $\mathrm{KCs}$ denotes a strong $\mathrm{Ca}^{2+}$ influx in KCs and rat basophilic leukemia cells transfected with the C5a receptor CD88 in response to C5a (Schlaf et al, 1999), which was not observed in rat basophilic leukemia cells transfected with C5L2 (Cain and Monk, 2002). To clearly identify the receptor or receptors involved in the mediation of $\mathrm{C5a}$ effects in $\mathrm{KCs}$, inhibitory antibodies against the rat C5a receptor CD88 or rat C5L2 should be employed. However, these antibodies are not available so far. 
Comparable to the receptors for $\mathrm{C} 5 \mathrm{a}$, the receptors most probably involved in the mediation of zymosan effects were predominantly expressed by KCs but not by hepatocytes (Fig. 5). Zymosan consists of different polysaccharides, mainly $\beta$-glucan and $\alpha$-mannan, and of very low amounts of protein and fat. The most actual reports claim dectin-1 (a $\beta$-glucan receptor) alone or in cooperation with TLR2 and TLR4 as relevant zymosan-signaling molecules (Brown et al, 2003; Gantner et al, 2003). All three receptors were expressed by KCs. Of course, the present study could not clarify whether the investigated receptors are functionally relevant for zymosan signaling in $\mathrm{KCs}$ or whether any other of the numerous discussed receptors, such as the peptidoglycan recognition protein (Liu et al, 2001), are (additionally) involved. However, because all of the investigated C5a or zymosan receptors were predominantly or even exclusively expressed by KCs but not by hepatocytes, the mRNA expression data support our functional data, showing no direct stimulation of hepatocytes by the proinflammatory substances but only by means of intercellular communication.

Zymosan or C5a reaching the liver via blood would first induce the release of soluble mediators such as prostanoids and cytokines from KCs. These cells, albeit located within the sinusoids, have protrusions that reach through the fenestrated endothelial layer into the space of Disse. As a consequence KCs can release soluble mediators directly into the space of Disse where they accumulate and exert their effector functions on the neighboring hepatocytes. By this intercellular signaling cascade, hepatocytes become an indirect target for the proinflammatory substances C5a and zymosan.

Our data have shown that due to the different kinetics and quantities of prostanoid release from $\mathrm{KCs}$, C5a, zymosan, or LPS play different roles in the regulation of glucose output and flow reduction, which are important liver-specific defense reactions.

\section{Materials and Methods}

\section{Animals}

Male Wistar-Unilever rats (Winkelmann, Borchen, Germany) weighing 150 to $200 \mathrm{~g}$ for perfusion experiments and 300 to $350 \mathrm{~g}$ for isolation of $\mathrm{KCs}$ were kept on a 12-hour day/night rhythm (light from 7:00 am to 7:00 pm) with free access to water and a standard rat diet (Ssniff, Soest, Germany) for at least 2 weeks before the experiment. Treatment of the animals followed the German law on the protection of animals.

\section{Chemicals}

Pronase was obtained from Merck (Darmstadt, Germany), and collagenase $\mathrm{H}$ and DNase were obtained from Roche (Mannheim, Germany). Nycodenz was purchased from Life Technologies (Eggenstein, Germany), RPMI 1640 from Biochrom (Berlin, Germany), newborn calf serum from PAA Laboratories (Coelbe, Germany), and tissue culture dishes from Nunc (Wiesbaden, Germany). Zymosan A from Sac- charomyces cerevisiae, LPS (Escherichia coli, O26:B6), and the $\mathrm{TXA}_{2}$ analog $\mathrm{U} 46619$ were delivered by SigmaAldrich (Deisenhofen, Germany), and $\left[{ }^{3} \mathrm{H}\right] \mathrm{PGD}_{2}{ }^{-}$ radioimmunoassay and $\left[1-{ }^{14} \mathrm{C}\right]$ arachidonic acid (activity 50 to $62 \mathrm{mCi} / \mathrm{mmol}$ ) were purchased from Amersham Pharmacia Biotech (Freiburg, Germany). ELISAs for $\mathrm{PGE}_{2}$ and $\mathrm{TXB}_{2}$ (the stable derivative of the actually secreted and biologically active $T X A_{2}$, which decomposes with a half-life of only 37 seconds to $\mathrm{TXB}_{2}$ ) (Smith, 1989) were from R\&D Systems (Wiesbaden-Nordenstadt, Germany). Silica gel plates (F1500, acid resistant) were obtained from Schleicher \& Schuell (Dassel, Germany). All other chemicals were of analytical grade and from commercial sources. Daltroban (BM 13.505: 4-[2-(4-chlorobenzenesulphonylamino)ethyl] benzene-acetic acid) was kindly provided by Roche. Recombinant rat C5a (rrC5a) was prepared as described previously (Rothermel et al, 1997).

\section{Perfusion of Isolated Rat Livers}

Liver perfusion experiments were started between 9:00 and 11:00 am. Livers were perfused in situ via the portal vein in a nonrecirculating manner, with an erythrocyte-free Krebs-Henseleit bicarbonate buffer containing $5 \mathrm{~mm}$ glucose, $2 \mathrm{~mm}$ lactate, and $0.2 \mathrm{~mm}$ pyruvate, equilibrated with $\mathrm{O}_{2}$ to $\mathrm{CO}_{2}(19: 1)$ at $37^{\circ} \mathrm{C}$ with constant hydrostatic pressure. The flow rate was adjusted to about $4 \mathrm{ml} / \mathrm{min} / \mathrm{g}$ liver. After 30 minutes preperfusion, livers were stimulated with $100 \mathrm{~nm}$ (1 $\mu \mathrm{g} / \mathrm{ml}$ ) $\mathrm{rrC5a}, 0.5 \mathrm{mg} / \mathrm{ml}$ zymosan, or $100 \mathrm{ng} / \mathrm{ml}$ LPS, respectively, for 30 seconds up to 5 minutes as indicated. To investigate the involvement of prostanoids, the prostanoid synthesis inhibitor indomethacin and the $\mathrm{TXA}_{2}$-receptor antagonist daltroban were dissolved in the perfusion medium to final concentrations of $20 \mu \mathrm{M}$ in $0.1 \%$ dimethyl sulfoxide each. Flow rates were determined once per minute, and aliquots of the perfusate were taken for the quantitation of glucose and prostanoid concentrations.

\section{Isolation and Culture of KCs}

KCs were isolated by combined pronase/collagenase liver perfusion and purified by density gradient centrifugation through $16.7 \%$ Nycodenz and subsequent counterflow elutriation using a Beckmann J-21 centrifuge with a Beckmann JE-6 elutriation rotor (Beckman-Coulter, Munich, Germany) (Brouwer et al, 1984). KCs $\left(4 \times 10^{6}\right.$ per dish) were plated on 35-mm culture dishes in RPMI 1640 supplemented with $30 \%$ newborn calf serum and $1 \%$ penicillin-streptomycin. KCs were cultured for 72 hours in the same medium, with daily medium changes. They were then determined to be $>99 \%$ pure by phagocytosis of fluorescent latex beads (Shaw et al, 1984) (fluoresbrite, diameter $1 \mu \mathrm{m}$; Polysciences, Eppelheim, Germany) and intracellular staining of added diaminobenzidine (Sigma-Aldrich) by endogenous peroxidases (Widman et al, 1972).

\section{Isolation and Culture of Hepatocytes}

Hepatocytes were prepared according to Meredith (1988) by $\mathrm{Ca}^{+}{ }^{+}$-free liver perfusion without the use of 
collagenase as described previously (Schieferdecker et al, 1997). Cells were plated at $0.5 \times 106$ cells/dish on 3.5-cm-diameter tissue culture dishes in M199 supplemented with $0.5 \mathrm{nmol} / \mathrm{L}$ insulin, $100 \mathrm{nmol} / \mathrm{L}$ dexamethasone, 1\% penicillin-streptomycin, and additional $4 \%$ newborn calf serum during the first 4 hours. Medium was changed after 4 hours and 24 hours, and RNA was isolated after 48 hours. Purity of hepatocytes as judged by their typical light microscopic appearance was $>98 \%$.

\section{Cell Culture Experiments}

For experiments lasting up to 1 hour, KCs were washed with and incubated in HBSS supplemented with $20 \mathrm{~mm}$ HEPES, pH 7.4; for longer lasting experiments, cells were kept in RPMI 1640 with 1\% penicillin-streptomycin, $\mathrm{pH}$ 7.4. Cells were preincubated for 10 minutes at $37^{\circ} \mathrm{C}$ and then stimulated with rrC5a, zymosan, or LPS added to final concentrations of $100 \mathrm{nM}(1 \mu \mathrm{g} / \mathrm{ml}), 0.5 \mathrm{mg} / \mathrm{ml}$, or $100 \mathrm{ng} / \mathrm{ml}$, respectively. Aliquots of cell culture supernatants were taken at the indicated time points and were immediately shock-frozen in liquid nitrogen. They were stored at $-20^{\circ} \mathrm{C}$ until determination of prostanoid concentrations.

\section{Biochemical Determinations}

Glucose concentrations were determined with a commercial enzyme test kit using glucose dehydrogenase (Granutest, Merck). DNA content per dish as a marker of the number of KCs per dish was determined by intercalation of bis-benzimide (Sigma-Aldrich), followed by fluorometric quantitation (Labarca and Paigen, 1980). Prostanoid concentrations in the cell culture supernatants and perfusion media were quantified without further purification by commercial radioimmunoassays $\left(\mathrm{PGD}_{2}\right)$ or ELISAs $\left(\mathrm{PGE}_{2}\right.$ and $\mathrm{TXB}_{2}$; See "Chemicals" section) or by thin layer chromatography as described previously (Pestel et al, 2002). For thin layer chromatography, phospholipids as prostanoid precursors were prelabeled by addition of $0.5 \mu \mathrm{Ci}\left[1-{ }^{14} \mathrm{C}\right]$ arachidonic acid to $\mathrm{KC}$ cultures 20 hours prior to the experiments. Labeled prostanoids were extracted from the cell culture supernatants with ethylacetate and were then separated on silica plates with the organic phase of ethylacetate:water:isooctane:acetate (110:100:50:20) (Hamberg and Samuelsson, 1966). The radioactivity of the synthesized $\left[1-{ }^{14} \mathrm{C}\right]$-labeled prostanoids was determined with a phosphorimager (Storm 860, Molecular Dynamics, Krefeld, Germany) and quantified with Image Quant (Molecular Dynamics) using diluted standards of $\left[1-{ }^{14} \mathrm{C}\right]$ arachidonic acid.

\section{Reverse Transcription PCR (RT-PCR)}

Total RNA from cultured KCs and hepatocytes was isolated by the RNeasy Kit provided by Qiagen (Hilden, Germany) and was purified from genomic DNA using the RNase-free DNase set (Qiagen). The isolated RNA was preincubated for 5 minutes at $70^{\circ} \mathrm{C}$ with 500 ng Oligo-d $(T)_{12-18}$ and transcribed into cDNA with RevertAid M-MuLV Reverse Transcriptase (MBI Fermentas, St. Leon-Rot, Germany). The cDNA thus generated was amplified in a $50-\mu$ l reaction mix containing $1.5 \mathrm{~mm} \mathrm{MgCl} 2,0.6 \mu \mathrm{M}$ of forward and reverse oligonucleotide primers (Table 1), $0.2 \mathrm{~mm}$ dNTPs, and $0.5 \mathrm{U}$ of thermostable TaqDNA polymerase (MBI Fermentas). For PCR, master mixes were prepared before adding the respective cDNAs. The cDNA was denatured for 3 minutes at $94^{\circ} \mathrm{C}$ and then subjected to 35 cycles of 1 minute at $94^{\circ} \mathrm{C}, 1$ minute at $58^{\circ} \mathrm{C}$ (TLR4), $56^{\circ} \mathrm{C}(\beta$-actin, C5L2, and dectin- 1$)$, or $52^{\circ} \mathrm{C}$ (TLR2), and 2 minutes at $72^{\circ} \mathrm{C}$, with a final elongation step of 10 minutes at $72^{\circ} \mathrm{C}$. After amplification, PCR products were separated on $2 \%$ agarose gels and visualized by ethidium bromide staining.

\section{References}

Alexander C and Rietschel ET (2001). Bacterial lipopolysaccharides and innate immunity. J Endotox Res 7:167-202.

Amatruda TT, Gerard NP, Gerard C, and Simon MI (1993). Specific interactions of chemoattractant factor receptors with G-proteins. J Biol Chem 268:10139-10144.

Birmelin M and Decker K (1984). Synthesis of prostanoids and cyclic nucleotids by phagocytosing rat Kupffer cells. Eur J Biochem 142:219-225.

Brandtzaeg P, Mollnes TE, and Kierulf P (1989). Complement activation and endotoxin levels in systemic meningococcal disease. J Infect Dis 160:58-65.

Brouwer A, Barelds RJ, and Knook DL (1984). Centrifugal separation of mammalian cells. In: Rickwood D, editor. Centrifugation: a practical approach. Oxford: IRL Press, 183-218.

Brown GD, Herre J, Williams DL, Willment JA, Marshall AS, and Gordon S (2003). Dectin-1 mediates the biological effects of beta-glucans. J Exp Med 197:1119-1124.

Buhl AM, Eisfelder BJ, Worthen GS, Johnson GL, and Russell M (1993). Selective coupling of the human anaphylatoxin C5a receptor and alpha 16 in human kidney 293 cells. FEBS Lett 323:132-134.

Cain SA and Monk PN (2002). The orphan receptor C5L2 has high affinity binding sites for complement fragments $\mathrm{C} 5 \mathrm{a}$ and C5a des-Arg(74). J Biol Chem 277:7165-7169.

Casteleijn E, Kuiper J, van Rooij HCJ, Kamps JAAM, Koster JF, and van Berkel TJC (1987). Endotoxin stimulates glycogenolysis in the liver by means of intercellular communication. J Biol Chem 263:6953-6955.

Dieter P, Altin JG, and Bygrave FL (1987a). Possible involvement of prostaglandins in vasoconstriction induced by zymosan and arachidonic acid in the perfused rat liver. FEBS Lett 213:174-178.

Dieter P, Altin JG, Decker K, and Bygrave FL (1987b). Possible involvement of eicosanoids in the zymosan and arachidonic-acid-induced oxygen uptake, glycogenolysis and $\mathrm{Ca}^{2+}$ mobilization in the perfused rat liver. Eur $\mathrm{J}$ Biochem 165:455-460.

Dieter P, Schulze-Specking A, and Decker K (1989). Signal transduction during stimulus-induced synthesis of prostanoids and superoxide in cultured rat Kupffer cells. In: Wisse E, Knook DL, Decker K, editors. Cells of the hepatic sinusoid, Vol 2. Rijswijk: The Kupffer Cell Foundation, 190-193. 
Gantner BN, Simmons RM, Canavera SJ, Akira S, and Underhill DM (2003). Collaborative induction of inflammatory responses by dectin-1 and toll-like receptor 2. J Exp Med 197:1107-1117.

Grewe M, Duyster J, Dieter P, Henniger H, Schulze-Specking $A$, and Decker $K$ (1992). Prostaglandin $D_{2}$ and $E_{2}$ syntheses in rat Kupffer cells are antagonistically regulated by lipopolysaccharide and phorbol ester. Biol Chem Hoppe Seyler 373:655-664.

Hamberg M and Samuelsson B (1966). Prostaglandins in human seminal plasma. Prostaglandins and related factors 46. J Biol Chem 241:257-263.

Hespeling U, Püschel GP, Jungermann K, Götze O, and Zwirner $J$ (1995). Stimulation of glycogen phosphorylase in rat hepatocytes via prostanoid release from Kupffer cells by recombinant rat anaphylatoxin C5a but not by native human C5a in hepatocyte/Kupffer cell co-cultures. FEBS Lett 372:108-112.

Kimura K, Shiota M, Mochizuki K, Ohta M, and Sugano T (1992). Different preparations of zymosan induce glycogenolysis independently in the perfused rat liver. Involvement of mannose receptors, peptide-leukotrienes and prostaglandins. Biochem J 283:773-779.

Labarca C and Paigen K (1980). A simple, rapid and sensitive DNA assay procedure. Anal Biochem 102:344-352.

Liu C, Xu Z, Gupta D, and Dziarski R (2001). Peptidoglycan recognition proteins: A novel family of four human innate immunity pattern recognition molecules. J Biol Chem 276: 34686-34694.

Mäck C, Jungermann K, Götze O, and Schieferdecker HL (2001). Anaphylatoxin C5a actions in rat liver: Synergistic enhancement by C5a of LPS-dependent $\alpha_{2}$-macroglobulin gene expression in hepatocytes via interleukin-6 release from Kupffer cells. J Immunol 167:3972-3979.

Meredith MJ (1988). Rat hepatocytes prepared with collagenase: Prolonged retention of differentiated characteristics in culture. Cell Biol Toxicol 4:405-425.

Muschol W, Püschel GP, Hülsmann M, and Jungermann $\mathrm{K}$ (1991). Eicosanoid-mediated increase in glucose and lactate output as well as decrease and redistribution of flow by complement-activated rat serum in perfused rat liver. Eur J Biochem 196:525-530.

Ohno M, Hirata T, Enomoto M, Araki T, Ishimaru $\mathrm{H}$, and Takahashi TA (2000). A putative chemoattractant receptor, C5L2, is expressed in granulocyte and immature dendritic cells, but not in mature dendritic cells. Mol Immunol 37:407412.

Pestel S, Jungermann K, Götze O, and Schieferdecker HL (2002). Inhibition by prostaglandin $E_{2}$ of anaphylatoxin C5abut not zymosan-induced prostanoid release from rat Kupffer cells. Lab Invest 82:463-471.

Peters T, Karck U, and Decker K (1990). Interdependence of tumor necrosis factor, prostaglandin $\mathrm{E}_{2}$, and protein synthesis in lipopolysaccharide-exposed Kupffer cells. Eur J Biochem 191:583-589.

Püschel GP and Jungermann K (1994). Integration of function in the hepatic acinus: Intercellular communication in neutral and humoral control of liver metabolism. Progr Liv Dis 12:19-46.
Püschel GP, Hespeling U, Oppermann M, and Dieter $P$ (1993). Increase in prostanoid formation in rat liver macrophages (Kupffer cells) by human anaphylatoxin C3a. Hepatol 18:1516-1521.

Püschel GP, Nolte A, Schieferdecker HL, Rothermel E, Götze O, and Jungermann K (1996). Inhibition of anaphylatoxin C3a- and C5a- but not nerve stimulation- or noradrenalindependent increase in glucose output and reduction of flow in Kupffer cell depleted perfused rat livers. Hepatol 24:685690.

Rothermel E, Rolf O, Götze O, and Zwirner J (1997). Nucleotide and corrected amino acid sequence of the functional recombinant rat anaphylatoxin $\mathrm{C} 5 \mathrm{a}$. Biochim Biophys Acta 1351:9-12.

Schieferdecker HL, Pestel S, Püschel GP, Götze O, and Jungermann K (1999). Increase by anaphylatoxin C5a of glucose output in perfused rat liver via prostanoids derived from nonparenchymal cells: Direct action of prostaglandins and indirect action of thromboxane $A_{2}$ on hepatocytes. Hepatology 30:454-461.

Schieferdecker HL, Pestel S, Rothermel E, Püschel GP, Götze O, and Jungermann K (1998). Stimulation by anaphylatoxin $\mathrm{C5a}$ of glycogen phosphorylase in rat hepatocytes via prostanoid release from hepatic stellate cells but not sinusoidal endothelial cells. FEBS Lett 434:245-250.

Schieferdecker HL, Rothermel E, Timmermann A, Götze O, and Jungermann K (1997). Anaphylatoxin C5a receptor mRNA is strongly expressed in Kupffer and stellate cells and weakly in sinusoidal endothelial cells but not in hepatocytes of normal rat liver. FEBS Lett 406:305-309.

Schlaf G, Schieferdecker HL, Rothermel E, Jungermann K, and Götze O (1999). Differential expression of the C5a receptor on the main cell types of rat liver as demonstrated with a novel monoclonal antibody and by $\mathrm{C} 5 \mathrm{a}$ anaphylatoxininduced $\mathrm{Ca}^{2+}$ release. Lab Invest 79:1287-1297.

Schromm AB, Brandenburg K, Rietschel ET, Flad H, Carroll SF, and Seydel U (1996). Lipopolysaccharide-binding protein mediates CD14-independent intercalation of lipopolysaccharide into phospholipid membranes. FEBS Lett 399:267-271.

Schulze M and Götze O (1986). A sensitive ELISA for the quantification of human $\mathrm{C} 5 \mathrm{a}$ in blood plasma using a monoclonal antibody. Complement 3:25-39.

Shaw RG, Johnson AR, Schulz WW, Zahlten RN, and Combes R (1984). Sinusoidal endothelial cells from normal guinea pig liver: Isolation, culture and characterization. Hepatol 4:591-602.

Siciliano SJ, Rollins TE, and Springer MS (1990). Interaction between the $\mathrm{C} 5 \mathrm{a}$ receptor and $\mathrm{Gi}$ in both the membranebound and detergent-solubilized states. J Biol Chem 265: 19568-19574.

Smith EF (1989). Thromboxane A2 in cardiovascular and renal disorders: Is there a defined role for thromboxane receptor antagonists or thromboxane synthase inhibitors? Eicosanoids 2:199-207.

Widman JJ, Cotran RS, and Fahimi HD (1972). Mononuclear phagocytes (Kupffer cells) and endothelial cells: Identification of two functional cell types in rat liver sinusoids by endogenous peroxidase activity. J Cell Biol 52:159-170. 